\title{
Evidence-Based Current Surgical Practice: Calculous Gallbladder Disease
}

\author{
Casey B. Duncan • Taylor S. Riall
}

Received: 1 May 2012 / Accepted: 15 August 2012 /Published online: 18 September 2012

(C) 2012 The Society for Surgery of the Alimentary Tract

\begin{abstract}
Background Gallbladder disease is common and, if managed incorrectly, can lead to high rates of morbidity, mortality, and extraneous costs. The most common complications of gallstones include biliary colic, acute cholecystitis, common bile duct stones, and gallstone pancreatitis. Ultrasound is the initial imaging modality of choice. Additional diagnostic and therapeutic studies including computed tomography, magnetic resonance imaging, magnetic resonance cholangiopancreatography, endoscopic ultrasound, and endoscopic retrograde cholangiopancreatography are not routinely required but may play a role in specific situations.

Discussion Biliary colic and acute cholecystitis are best treated with early laparoscopic cholecystectomy. Patients with common bile duct stones should be managed with cholecystectomy, either after or concurrent with endoscopic or surgical relief of obstruction and clearance of stones from the bile duct. Mild gallstone pancreatitis should be treated with cholecystectomy during the initial hospitalization to prevent recurrence. Emerging techniques for cholecystectomy include single-incision laparoscopic surgery and natural orifice transluminal endoscopic surgery. Early results in highly selected patients demonstrate the safety of these techniques. The management of complications of the gallbladder should be timely and evidence-based, and choice of procedures, particularly for common bile duct stones, is largely influenced by facility and surgeon factors.
\end{abstract}

Keywords Evidence-based $\cdot$ Surgery $\cdot$ Gallbladder $\cdot$ Biliary

\section{Introduction}

Gallstone disease is the most costly digestive disease in the USA, with an estimated annual cost of $\$ 5$ billion. ${ }^{1,2}$ Approximately 20 million people in the USA have gallstones, leading to over one million hospitalizations and 700,000 operative procedures per year. ${ }^{1-3}$ Gallstones are present in approximately $6.5 \%$ of men and $10.5 \%$ of women. ${ }^{3,4}$ The prevalence of gallstones increases with age. By age 70, $15 \%$ of men and $24 \%$ of women have gallstones, with these numbers increasing to 24 and $35 \%$, respectively, by the age of 90 (Fig. 1). ${ }^{4-6}$

\section{B. Duncan · T. S. Riall $(\triangle)$}

Department of Surgery, The University of Texas Medical Branch, 301 University Boulevard,

Galveston, TX 77555-0541, USA

e-mail: tsriall@utmb.edu
Over $70 \%$ of patients with gallstones are asymptomatic. $^{3,4,7-9}$ The risk of developing symptoms or complications related to gallstones is approximately $1-4 \%$ per year. ${ }^{7,8}$ The most common complications of gallstone disease are biliary colic, acute cholecystitis, common bile duct stones, and gallstone pancreatitis. Less common complications include empyema of the gallbladder, liver abscess, gallbladder perforation with bile peritonitis, cholangitis, cholecystoenteric fistula, and gallstone ileus.

Biliary colic occurs when the gallbladder contracts against a stone which is transiently obstructing the cystic duct. $^{3}$ Patients with biliary colic complain of sharp, intermittent, cramping right upper quadrant pain, pain radiating to the right shoulder, nausea, and vomiting. The pain occurs most commonly after a fatty meal and may last for several hours. $^{1,3,7}$

Acute cholecystitis occurs when the cystic duct becomes obstructed by a gallstone, leading to gallbladder distention, serosal edema, mucosal sloughing, venous and lymphatic congestion, and ischemia. Patients with acute cholecystitis 


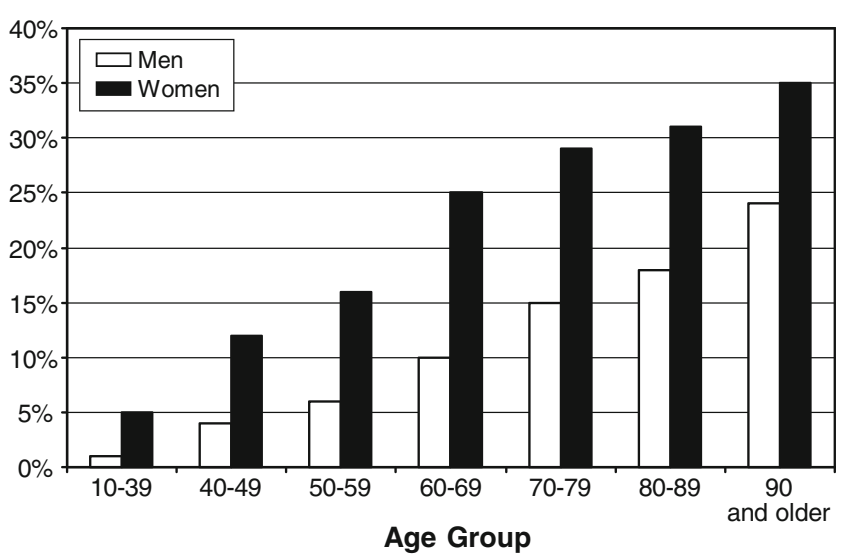

Fig. 1 Prevalence of gallstones by age and gender

complain of unresolving right upper quadrant pain, nausea, vomiting, anorexia, and fever. Leukocytosis is common, ${ }^{3,10,11}$ while alkaline phosphatase and bilirubin are typically normal. ${ }^{3,12-14}$ Elevated liver function tests (LFTs) are associated with worse outcomes in patients with acute cholecystitis. ${ }^{15}$ Kimura et al., in a large review of the literature, report mortality and complication rates of acute cholecystitis ranging $0-10$ and 7-26\%, respectively., ${ }^{3,16}$ Perforation of the gallbladder occurs in 5-10 \% of cases of acute cholecystitis. ${ }^{3,17}$ Perforation is caused by necrosis of an ischemic area of the wall of the gallbladder and is associated with a high mortality rate. ${ }^{18}$

Common bile duct (CBD) stones (choledocholithiasis) are identified in approximately $10 \%$ of patients with cholelithiasis and $5-18 \%$ of patients undergoing elective cholecystectomy. ${ }^{3,14,19-21}$ Associated signs include jaundice, acholic stools, and dark urine. ${ }^{3,14}$ Patients with common bile duct stones can present with acute cholangitis, manifested by fever, jaundice, and right upper quadrant pain. Acute cholangitis is a surgical emergency and prompt biliary decompression is necessary.

Gallstones are one of the leading causes of acute pancreatitis and may be the first manifestation of gallstone disease in up to $40 \%$ of patients with gallstones. ${ }^{12,13,22}$ Patients with gallstone pancreatitis present with epigastric abdominal pain, nausea, and vomiting, and may or may not have a history of previous gallbladder-related symptoms. Severe pancreatitis occurs in approximately 10-25\% of patients with gallstone pancreatitis. ${ }^{12,13,23}$

In patients fit for surgery, cholecystectomy, either laparoscopic or open, is the only definitive treatment for gallstones. When cholecystectomy is not performed, recurrence of gallstone-related symptoms, complications, readmissions, and death can occur. ${ }^{7,23-31}$ Dietary modification and medical therapy for symptomatic gallstones, endoscopic treatment of common bile duct stones and gallstone pancreatitis, and percutaneous gallbladder drainage for acute cholecystitis are alternative measures in patients who are not fit for surgery. These measures decrease but do not eliminate recurrence of gallstone-related complications.

The goal of this paper is to review the evidence-based management of complicated gallstone disease, specifically focusing on controversies in management and advances in surgical technique. The discussion of the symptoms, imaging, and laboratory manifestations of gallbladder disease will be limited.

\section{Diagnostic Imaging}

Table 1 portrays the recommended imaging and subsequent management for diseases of the gallbladder.

\section{Right Upper Quadrant Ultrasound}

Right upper quadrant ultrasound is the imaging modality of choice for suspected gallbladder disease due to low cost, availability, and lack of radiation exposure. ${ }^{32}$ Sonographically, gallstones appear as hyperechoic, mobile structures with acoustic shadowing (Fig. 2). Ultrasound has a sensitivity and specificity greater than $95 \%$ in the detection of gallstones. ${ }^{1,3,8,33,34}$ Ultrasound can identify gallbladder wall thickening (>4-5 mm; Fig. 2) and edema (double-wall sign), gallbladder sludge, pericholecystic fluid, and a sonographic Murphy's sign, consistent with acute cholecystitis. ${ }^{3,15,35,36}$ When these signs are present, the positive predictive value of ultrasound in the diagnosis of acute cholecystitis is $>90 \%$ and additional studies are rarely needed. ${ }^{36}$

Dilatation of the common bile duct $(>8 \mathrm{~mm})$ and gallstones on ultrasound with associated jaundice and abnormal LFTs are indicative of choledocholithiasis. ${ }^{3,14}$ While large common bile duct stones can be identified, small stones may be difficult to visualize sonographically. If suspected clinically, additional imaging such as magnetic resonance cholangiopancreatography (MRCP), endoscopic retrograde cholangiopancreatography (ERCP), or intraoperative cholangiography (IOC) should be obtained to diagnose and treat choledocholithiasis, gallstone pancreatitis, or cholangitis. ${ }^{8,12,13,37}$

\section{Computed Tomography}

Ultrasound is preferred over computed tomography (CT) scanning in the diagnosis of suspected gallbladder disease as greater than $60 \%$ of gallstones are not radiopaque. ${ }^{32,36,38}$ Similarly, CT has been shown to be less sensitive and specific in the diagnosis of cholecystitis. ${ }^{32,34,39}$ More than $50 \%$ of patients with clinical signs of pancreatitis or common bile duct stones do not have gallstones identified on CT scan; subsequent ultrasound identifies gallstones in almost $90 \%$ of these patients. ${ }^{33}$ 
Table 1 Diagnostic imaging and management of diseases of the gallbladder

\begin{tabular}{|c|c|c|c|c|c|c|c|}
\hline & $\begin{array}{l}\text { Biliary } \\
\text { colic }\end{array}$ & $\begin{array}{l}\text { Acalculous } \\
\text { cholecystitis }\end{array}$ & $\begin{array}{l}\text { Acute } \\
\text { cholecystitis }\end{array}$ & $\begin{array}{l}\text { Common bile } \\
\text { duct stones }\end{array}$ & $\begin{array}{l}\text { Gallstone } \\
\text { pancreatitis (mild) }\end{array}$ & $\begin{array}{l}\text { Gallstone } \\
\text { pancreatitis (severe) }\end{array}$ & $\begin{array}{l}\text { Acute } \\
\text { cholangitis }\end{array}$ \\
\hline \multicolumn{8}{|l|}{ Diagnostic imaging } \\
\hline Ultrasound & $\mathrm{X}$ & $\mathrm{X}$ & $\mathrm{X}$ & $\mathrm{X}$ & $\mathrm{X}$ & $X$ & \\
\hline \multicolumn{8}{|l|}{ Computed tomography } \\
\hline $\begin{array}{l}\text { Magnetic resonance } \\
\text { cholangiopancreatography }\end{array}$ & & & & $X$ & $\mathrm{X}$ & $X$ & $\mathrm{X}$ \\
\hline $\begin{array}{l}\text { Endoscopic retrograde } \\
\text { cholangiopancreatography }\end{array}$ & & & & $X$ & $X$ & $\mathrm{X}$ & $\mathrm{X}$ \\
\hline Endoscopic ultrasound & & & & $\mathrm{X}$ & & & \\
\hline $\begin{array}{l}\text { Hepatobiliary iminodiacetic } \\
\text { acid scan }\end{array}$ & & $X$ & $\mathrm{X}$ & & & & \\
\hline \multicolumn{8}{|l|}{ Management } \\
\hline Early cholecystectomy & $\mathrm{X}$ & $\mathrm{X}$ & $\mathrm{X}$ & $\mathrm{X}$ & $\mathrm{X}$ & & \\
\hline Delayed cholecystectomy & & & & & & $\mathrm{X}$ & $\mathrm{X}$ \\
\hline $\mathrm{ERCP}^{\mathrm{a}}$ & & & & $X^{a}$ & & $X^{a}$ & $\mathrm{X}$ \\
\hline $\begin{array}{l}\text { Intraoperative } \\
\text { cholangiogram }\end{array}$ & & & & $\mathrm{X}$ & & & \\
\hline Cholecystostomy & & $-{ }^{\mathrm{b}}$ & $-{ }^{\mathrm{b}}$ & & & & \\
\hline
\end{tabular}

Excluding patients with porcelain gallbladder, gallstones $>3 \mathrm{~cm}$ in size, heart transplant candidates, and those undergoing additional abdominal procedures

${ }^{a}$ Therapeutic ERCP may be performed in patients with common bile duct stones or mild or severe pancreatitis who are not surgical candidates

${ }^{\mathrm{b}}$ Cholecystostomy may be performed in patients with cholecystitis who are not surgical candidates

CT scanning is currently recommended when diagnostic uncertainty exists and the physician suspects other intraabdominal pathology. ${ }^{39}$ Despite these recommendations, a recent single-institution study demonstrated that $46 \%$ of patients presenting with acute gallbladder disease underwent CT scanning, with $25 \%$ of patients undergoing both ultrasound and $\mathrm{CT}^{33}$ Patients who were older, male, and who had an elevated WBC were more likely to undergo CT. In $34.3 \%$ of patients undergoing CT, the history was consistent with gallstone disease and there was no clear indication

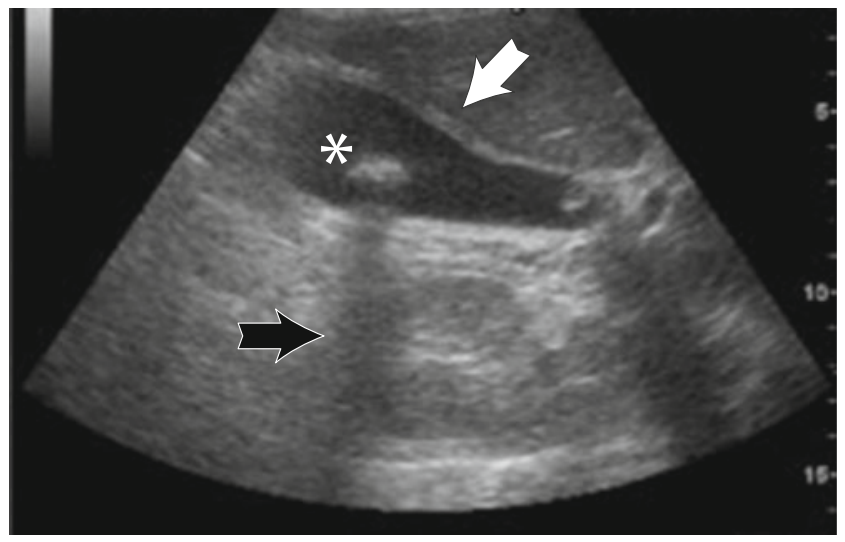

Fig. 2 Transabdominal ultrasound demonstrating gallstones (asterisk) with classic acoustic shadowing (short black arrow) and gallbladder wall thickening (short white arrow) for scanning. Most concerning was that patients imaged between $7 \mathrm{pm}$ and $7 \mathrm{am}$ were over four times more likely to undergo CT scanning, suggesting that the availability of ultrasound and/or CT scanning and not patient and disease characteristics were driving overuse. ${ }^{33}$ Given the ready availability of CT scans, this problem is likely more widespread and should be studied at the population level.

\section{Magnetic Resonance Imaging and Magnetic Resonance Cholangiopancreatography}

Magnetic resonance imaging and MRCP are useful in identifying CBD stones and delineating pancreatic and biliary tract anatomy (Fig. 3). MRCP can be useful in the evaluation of a pregnant patient with right upper quadrant pain. ${ }^{36}$ CBD stones, if identified on MRCP, cannot be removed, necessitating additional therapeutic procedures such as ERCP or common bile duct exploration. Conversely, if MRCP is negative, the complications associated with these more invasive procedures can be avoided. The cost of MRCP should limit its use in the diagnosis of gallstones and acute cholecystitis. ${ }^{1,3,8,14,34,37,40,41}$

\section{Endoscopic Retrograde Cholangiopancreatography}

ERCP is considered the gold standard in the detection of common bile duct stones, with a sensitivity and specificity 


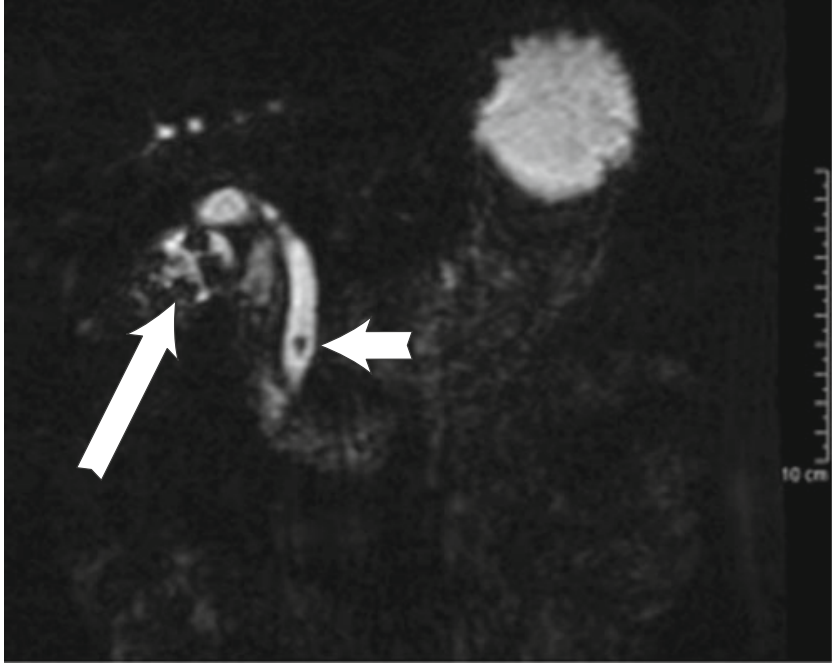

Fig. 3 MRCP demonstrating filling defects in the gallbladder consistent with gallstones (long arrow) and a solitary filling defect in the common bile duct (short arrow)

approaching $95 \%,{ }^{3,14,34,37}$ and has the advantage of being both diagnostic and therapeutic for the removal of CBD stones. ERCP is also useful in clarifying biliary anatomy when unclear. However, ERCP is not without associated risks. The overall complication rate for ERCP ranges from 0.8 to $11.1 \%$, although therapeutic ERCP is associated with a higher complication rate compared to diagnostic ERCP. ${ }^{42-45}$ ERCP-induced pancreatitis occurs in $0.2-$ $5.2 \%$ of procedures and is typically mild or moderate. ${ }^{43-45}$ Hemorrhage $(0.2-1.9 \%)$, perforation $(0.2-1.0 \%)$, and cholangitis $(0.1-2.1 \%)$ are less commonly encountered. ${ }^{43-45}$ Increasing age, sphincterotomy technique, failure to clear the bile duct, and obstruction of the ampulla of Vater have been associated with an increased risk of ERCP-induced complications. ${ }^{43}$ ERCP-related mortality rates range from 0.1 to $3.3 \%,{ }^{42,44,45}$ and age greater than 60 years has been associated with increased risk of ERCP-related death. ${ }^{45}$ The role and timing of ERCP in the management of known or suspected CBD stones is discussed in detail below.

\section{Endoscopic Ultrasound}

Due to its high-frequency resolution, endoscopic ultrasound (EUS) can detect small gallstones and common bile duct stones. ${ }^{1,8,14,40}$ In a large review, O'Neill et al. report a sensitivity of EUS of greater than $96 \%$ for identification of both occult cholelithiasis and choledocholithiasis, higher than that of both transabdominal ultrasound and $\mathrm{CT}^{40}$ In addition, EUS and ERCP have been shown to have equivalent sensitivity and specificity in the detection of common bile duct stones. ${ }^{40}$ In patients with low or intermediate probability of common duct stones, EUS is recommended as the initial test, reserving ERCP for patients with known or high probability of common duct stones and who would likely require intervention for stone removal. ${ }^{37,40}$

Hepatobiliary Iminodiacetic Acid Scan

Hepatobiliary iminodiacetic acid (HIDA) scanning is used for the diagnosis of acute cholecystitis, chronic cholecystitis, acalculous cholecystitis, and biliary dyskinesia. After administration of cholecystokinin (CCK), nonvisualization of the gallbladder on HIDA scan is consistent with acute cholecystitis, while visualization of the gallbladder virtually excludes the diagnosis. ${ }^{36}$ Morphine injection during HIDA scan may distinguish between chronic cholecystitis (visualization within 20-30 min of injection) and acute cholecystitis (persistent nonvisualization after injection). ${ }^{36}$ The "rim sign," caused by increased pericholecystic hepatic uptake of radioactive tracer, is indicative of gangrenous cholecystitis. ${ }^{36}$ After CCK injection, a gallbladder ejection fraction of less than $40 \%$ and reproduction of abdominal pain support the diagnosis of biliary dyskinesia. ${ }^{32,46,47}$

Keeping this in mind, HIDA scanning is not the primary modality used in the diagnosis of acute calculous cholecystitis and should be reserved for cases in which the diagnosis is unclear or cholecystitis is being ruled out. ${ }^{3,36,47-49}$ HIDA scan is indicated when gallstones are not seen on ultrasound and the clinical picture is consistent with cholecystitis. In this scenario, nonvisualization of the gallbladder, with or without morphine injection, is consistent with acalculous cholecystitis. ${ }^{32,50-52}$ Accumulation of radioactive tracer in the gallbladder fossa may occur with gallbladder perforation. ${ }^{50}$ However, bile stasis, poor gallbladder contractility, analgesics, or hepatocellular disease may result in a false-positive HIDA scan, making this modality less helpful in critically ill patients. ${ }^{3,36,51}$

\section{Controversies in Management}

\section{Management of Asymptomatic Gallstones}

Because of the increase in the use of imaging for various disease processes, the identification of asymptomatic gallstones is becoming more common. The majority of patients with asymptomatic gallstones will remain asymptomatic, with only $2-4 \%$ of patients developing symptoms annually. ${ }^{1,9,53}$ The complication rate (acute cholecystitis, choledocholithiasis, gallstone pancreatitis) in asymptomatic patients ranges from 0.7 to $3 \%$ per year. ${ }^{1,7,9}$ Given the lowincidence of symptoms and complications in patients with incidentally identified asymptomatic gallstones, prophylactic cholecystectomy is not currently recommended. ${ }^{1,7,9}$

There are several situations in which cholecystectomy for asymptomatic gallstones should be considered. Patients with porcelain gallbladder and those with gallstones greater than 
$3 \mathrm{~cm}$ in size are at increased risk for cancer and should undergo cholecystectomy. Prophylactic cholecystectomy has also been advocated in patients with asymptomatic gallstones prior to organ transplant, most commonly heart transplant candidates, due to high rates of symptomatic gallstones and operative morbidity and mortality post-transplant. ${ }^{54,55}$ Pretransplant laparoscopic cholecystectomy can be performed safely in stable patients, including those awaiting a heart transplant. ${ }^{54,55}$ Patients with chronic hemolytic syndromes, including sickle cell anemia, should undergo cholecystectomy for asymptomatic gallstones. Historically, prophylactic cholecystectomy was performed in diabetic patients with asymptomatic gallstones to prevent severe biliary and infectious complications experienced by these patients. However, after adjusting for associated comorbidities (renal, vascular, cardiac disease), diabetes has not been shown to be a significant predictor of gallstone complications. Expectant management of asymptomatic gallstones in diabetic patients is now the treatment of choice. ${ }^{56-58}$ Finally, cholecystectomy should be considered if gallstones are identified during an abdominal operation for an unrelated reason; however, this depends on the type and reason for the operation being performed, the stability of the patient, and multiple other factors. ${ }^{7,9}$

\section{Timing of Cholecystectomy in Acute Gallbladder Disease}

Biliary Colic Patients with biliary colic should undergo cholecystectomy as soon as possible to avoid the possibility of future gallstone-related complications. ${ }^{3,7}$ A Cochrane review evaluated patients with biliary colic who underwent early (within $24 \mathrm{~h}$ of diagnosis) versus delayed laparoscopic cholecystectomy. ${ }^{25}$ The mean waiting time between randomization and delayed surgery was 4.2 months. In the waiting period, $23 \%$ of patients in the delayed group were admitted for pancreatitis, empyema of the gallbladder, gallbladder perforation, acute cholecystitis, cholangitis, and obstructive jaundice, while no patients in the early cholecystectomy group experienced a complication. Early laparoscopic cholecystectomy for biliary colic can prevent recurrent emergency department visits and complications. It has also been shown to be associated with a lower rate of conversion to an open procedure, shorter operating time, and shorter postoperative length of stay and is thus the procedure of choice. ${ }^{7,25}$

Acute Cholecystitis After the introduction of laparoscopic cholecystectomy in the late 1980s, the timing of cholecystectomy for acute cholecystitis (Fig. 4) became controversial. Acute inflammation makes cholecystectomy, laparoscopic or open, more difficult. During the early learning curve of laparoscopic cholecystectomy, there was concern that the conversion rates to open cholecystectomy and the incidence of bile duct injuries would be high during the acute phase. Many authors recommended antibiotics and delayed cholecystectomy such that patients would reap the benefits of laparoscopic cholecystectomy, including
Fig. 4 Management algorithm for acute cholecystitis. Laparoscopic cholecystectomy is preferred in all cases, but conversion to open may be necessary and should not be considered a failure in management

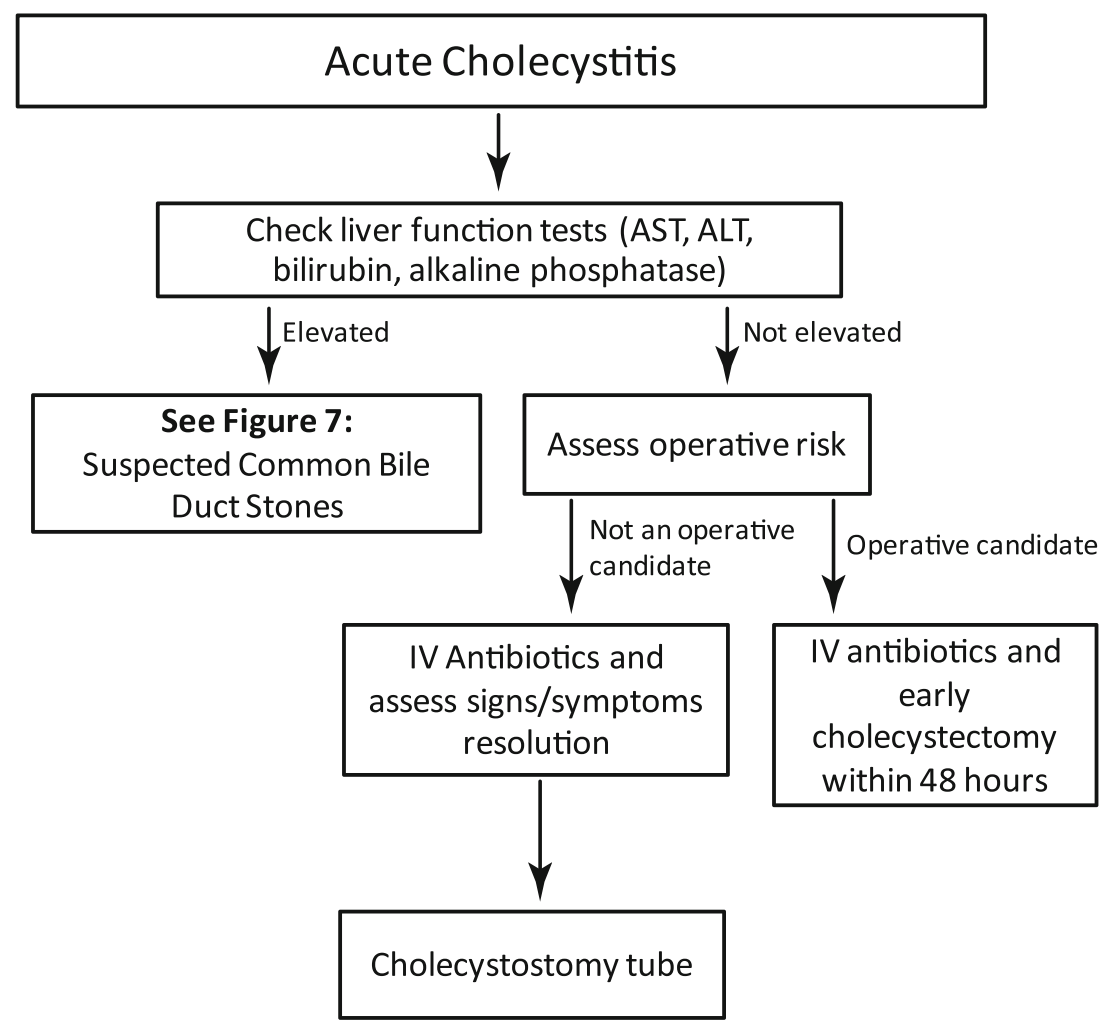


decreased pain, shorter lengths of stay, earlier return to work, and improved cosmesis. ${ }^{59,60}$ A Cochrane review compared early (within 7 days of presentation) to late ( $>6$ weeks after presentation) laparoscopic cholecystectomy for acute cholecystitis. ${ }^{24}$ The review included five randomized, controlled trials with 451 patients. In patients undergoing early cholecystectomy, the relative risk of bile duct injury was 0.64 ( $95 \%$ confidence interval $(\mathrm{CI})=0.15-2.65)$. The total hospital stay, including initial hospitalization and subsequent cholecystectomy or gallstone-related readmissions, was 4 days shorter for the early cholecystectomy group (mean difference $=-4.12$ days, $95 \% \mathrm{CI}=-5.22$ to -3.03 days). In addition, no differences in postoperative infection, bile duct injury, or conversion to open cholecystectomy have been demonstrated between patients undergoing early versus late cholecystectomy for acute cholecystitis. ${ }^{24}$

Cholecystectomy during index admission for acute cholecystitis is associated with decreased in-hospital mortality, long-term mortality, and gallstone-related readmission rates. ${ }^{7,28}$ Patients who do not undergo cholecystectomy during initial hospitalization for acute cholecystitis experience recurrence rates of gallstone complications ranging from 20 to $50 \%{ }^{28,61-70}$ In a study of 29,818 Medicare beneficiaries who were urgently or emergently admitted for acute cholecystitis, $25 \%$ of them did not undergo cholecystectomy during the index admission. Lack of definitive therapy was associated with a $27-\%$ subsequent cholecystectomy rate and a $38-\%$ gallstone-related readmission rate in the 2 years after discharge compared to only $4 \%$ in patients undergoing cholecystectomy $(p<0.0001)$. No cholecystectomy on initial hospitalization was associated with worse 2-year survival (HR=1.56, $95 \%$ CI 1.47-1.65) even after controlling for patient demographics and comorbidities. Readmissions were costly, with an additional $\$ 7,000$ in Medicare payments per readmission. ${ }^{28}$ Patients fit for surgery should undergo cholecystectomy during the index admission. In those who are poor candidates, the risk of recurrent gallbladder problems must be weighed against the operative risk.

Common Bile Duct Stones and Gallstone Pancreatitis Recurrence of gallstone-related complications after an initial hospitalization for CBD stones ranges from 40 to $50 \%$ for common bile duct stones. ${ }^{71,72}$ Therefore, once clearance of the common bile duct has occurred, cholecystectomy is recommended as soon as possible to avoid recurrence. $\mathrm{ERCP} /$ sphincterotomy without cholecystectomy is associated with increased mortality and a high number of readmissions in patients with common bile duct stones and should not be used as a definitive treatment in patients who can tolerate surgery. ${ }^{7,31}$ Current national data show that patients admitted urgently or emergently with CBD stones have $68 \%$ lower odds of undergoing cholecystectomy $(\mathrm{OR}=$
$0.32,95 \% \mathrm{CI}=0.30-0.34){ }^{28}$ This is likely because these patients are palliated with ERCP and stone removal. While these measures lower the risk of recurrent CBD stones, they do not eliminate it and do not reduce the risk of other gallstone-related complications such as acute cholecystitis. ${ }^{23}$

The International Association of Pancreatology recommends cholecystectomy during the same admission for patients with mild gallstone pancreatitis. ${ }^{22}$ The recurrence of gallstone-related problems after an initial episode of gallstone pancreatits is $25-63 \%$ without cholecystectomy. ${ }^{22,73-76}$ Laparoscopic cholecystectomy can be performed safely in patients with mild gallstone pancreatitis ( $<3$ Ranson criteria), typically after resolution of abdominal pain and normalization of laboratory values. ${ }^{7}$ Currently, cholecystectomy rates during the same admission in patients with mild pancreatitis range from 51 to $68 \%,{ }^{23,26,77,78}$ with population-based studies demonstrating rates of just over $50 \%{ }^{23,78}$ Patients who undergo cholecystectomy during index admission for mild gallstone pancreatitis are less likely to require gallstonerelated readmission ( 44 vs. $4 \%, p<0.0001$ ) and have lower 2 -year mortality rates compared to patients who do not undergo cholecystectomy. ${ }^{23}$ In addition, ERCP reduces, but does not eliminate, readmissions in patients without cholecystectomy, with patients undergoing ERCP having a 47-\% lower chance of readmission $(\mathrm{OR}=0.53,95 \% \mathrm{CI}=0.47-0.61)$. However, the data also showed that ERCP was less common in the no-cholecystectomy group ( 34 vs. $28 \%, p<0.0001$ ), suggesting that practice patterns rather than clinical condition dictate treatment. ${ }^{23}$

For patients with severe pancreatitis, surgery during the same admission is associated with higher morbidity and mortality. ${ }^{22}$ Therefore, cholecystectomy in patients with severe gallstone pancreatitis should be delayed for several weeks to allow for resolution of inflammation and organization of peripancreatic fluid collections. Surgical intervention during the acute phase of severe gallstone pancreatitis should be reserved for cases of infected pancreatic necrosis. ${ }^{13,22}$ In patients with mild or severe gallstone pancreatitis who are not candidates for surgery, ERCP with endoscopic sphincterotomy decreases the risk of recurrent pancreatitis and readmission. ${ }^{22,23}$

\section{Management of CBD Stones}

Approximately $10 \%$ of patients who undergo cholecystectomy for symptomatic gallstones have CBD stones (Fig. 5). ${ }^{14,19-21}$ Strategies for the management of suspected CBD stones (with or without pancreatitis) include cholecystectomy (laparoscopic or open) with expectant management, preoperative ERCP followed by cholecystectomy, cholecystectomy followed by ERCP, or cholecystectomy with intraoperative cholangiography and CBD exploration. Both ERCP and CBD exploration are safe and equally efficacious 


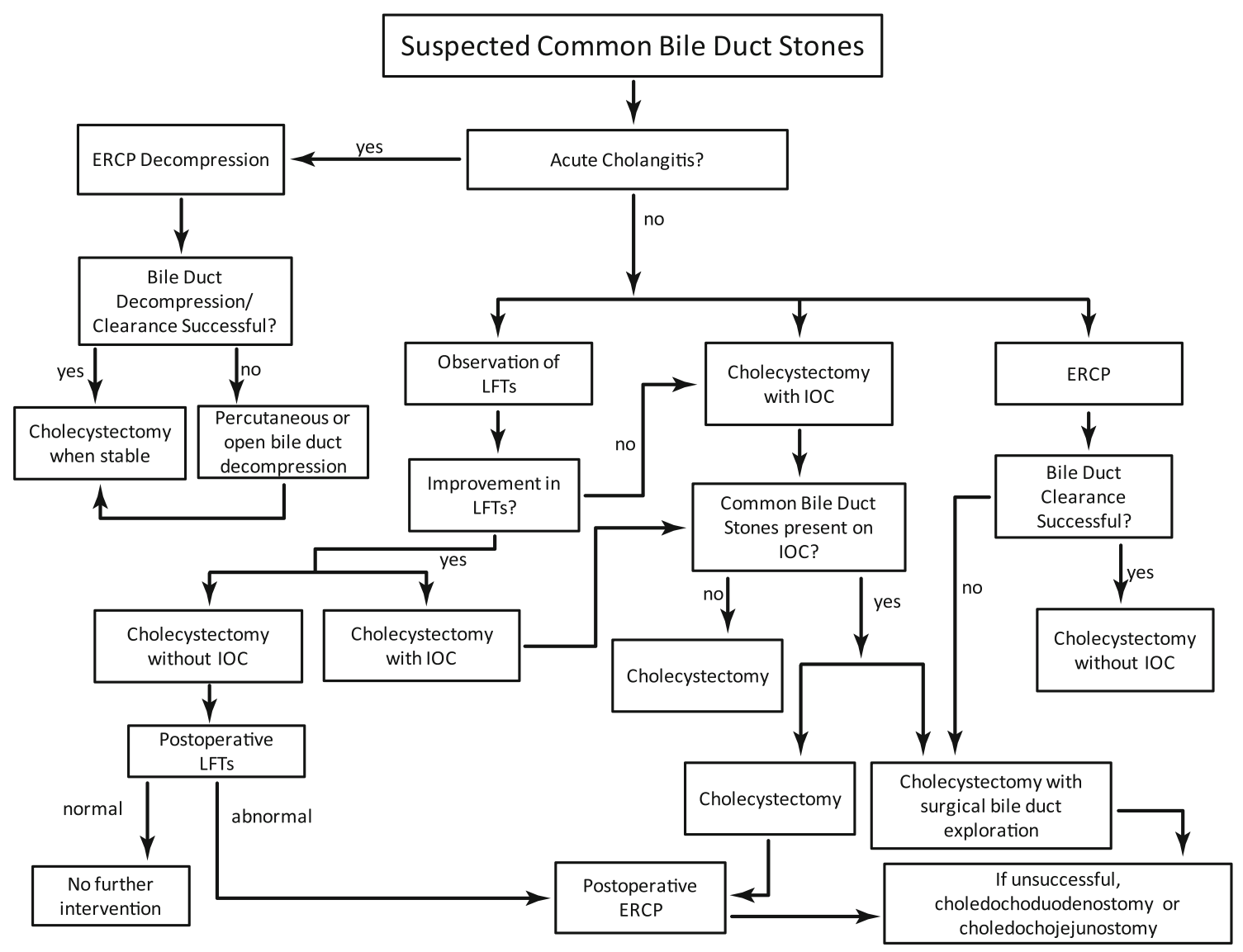

Fig. 5 Management algorithm for suspected common bile duct stones. Laparoscopic cholecystectomy is preferred in all cases, but conversion to open may be necessary and should not be considered a failure in management

in the removal of CBD stones, ${ }^{79-81}$ and the choice of treatment is often based on surgeon and endoscopist expertise within a given practice setting.

ERCP can be used to achieve bile duct clearance prior to laparoscopic cholecystectomy, or after cholecystectomy when common bile duct stones are identified on IOC and not removed by bile duct exploration. The "endoscopy first" method can be performed when there is a high-suspicion of common bile duct stones as ERCP can achieve bile duct clearance in up to $97 \%$ of patients, ${ }^{14,82,83}$ avoiding the need for a bile duct exploration intraoperatively. However, more than one endoscopic procedure may be required, and the use of preoperative ERCP has been associated with longer total hospital and postoperative stays. ${ }^{14,19,83}$ Both methods have been shown to be equally efficacious with regard to bile duct clearance. No differences have been shown with regards to perioperative and postoperative morbidity and mortality between the "endoscopy first" and "laparoscopy first" methods for the management of common bile duct stones. ${ }^{19}$ Routine preoperative ERCP may result in a high number of unnecessary procedures in patients whose common bile duct stones have passed at the time of endoscopy. ${ }^{19,80}$
Alternatively, if stones are suspected preoperatively, the surgeon can proceed directly to laparoscopic cholecystectomy with planned IOC. When common bile duct stones are identified at the time of cholecystectomy (Fig. 6), surgeons must choose between postoperative ERCP and CBD exploration. Both are efficacious, with ERCP success rates of over $75 \%$. However, if ERCP is unsuccessful postoperatively, a second anesthetic and CBD exploration may be necessary. ${ }^{14,19}$

Two analyses have evaluated the cost-effectiveness of various methods of CBD stone management. Both studies concluded that laparoscopic cholecystectomy with IOC (and bile duct exploration if stones are identified) is the superior management option. ${ }^{20,21}$ However, these models fail to take into account local expertise and assume universal surgeon ability with laparoscopic common bile duct exploration and endoscopic stone removal. Postoperative ERCP should be performed when operative bile duct exploration cannot be completed, either due to facility or surgeon limitations. ${ }^{21}$ Preoperative ERCP (or ERCP only) is advocated when the predicted operative morbidity or mortality is high, as in the case with high-risk patients, where cholecystectomy may be avoided indefinitely. ${ }^{14,20,31}$ 


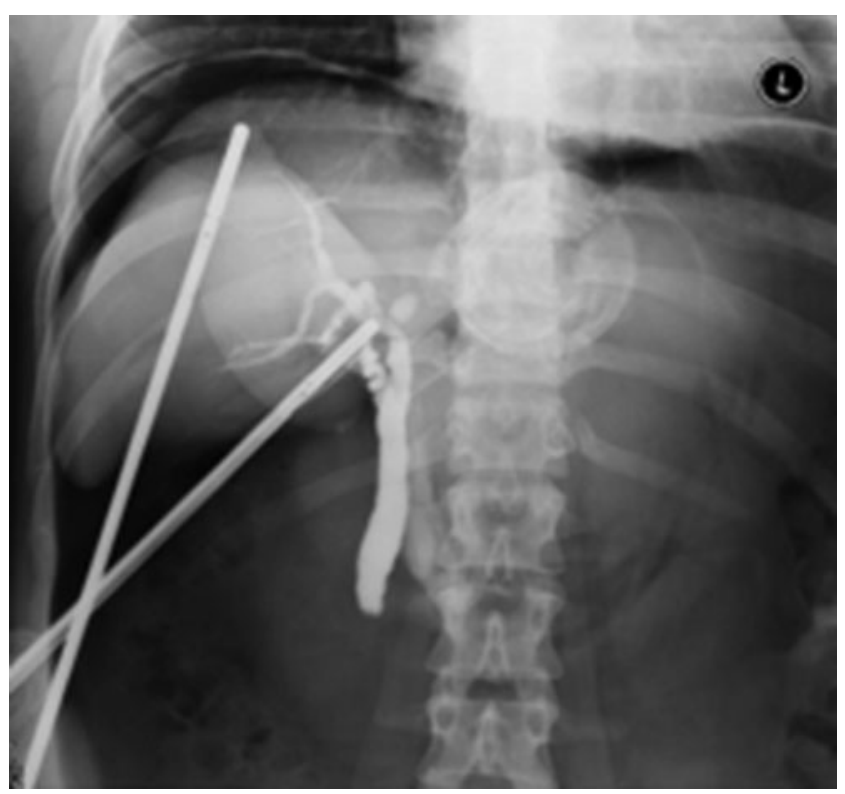

Fig. 6 Intraoperative cholangiogram demonstrating lack of flow of contrast into the duodenum consistent with distal obstruction by a small stone

Recently, the use of intraoperative ERCP has been advocated as an alternative to both preoperative ERCP and operative bile duct exploration. Gurusamy et al., ${ }^{82}$ in a large systematic review and meta-analysis, reported no difference with regards to bile duct clearance, operative morbidity, conversion to an open procedure, or operative time between ERCP followed by cholecystectomy and cholecystectomy with intraoperative ERCP. The use of intraoperative ERCP was associated with decreased ERCP-associated complications, total hospital stay, and total hospital costs. ${ }^{82}$ However, this method may be limited by difficulty in coordinating endoscopist and surgeon schedules and the supine position of the patient on the operating table. ${ }^{82,83}$

\section{ERCP in Gallstone Pancreatitis}

ERCP has a sensitivity and specificity greater than $90 \%$ in the detection of gallstones in patients with gallstone pancreatitis, ${ }^{12}$ although it has also been demonstrated that the majority of gallstones that cause pancreatitis pass spontaneously prior to ERCP (Fig. 7) ${ }^{84}$ A recent meta-analysis demonstrated no difference in morbidity or mortality between those patients who underwent early ERCP (within 48-72 h of admission) versus conservative management for gallstone pancreatitis, ${ }^{85}$ and the use of routine preoperative ERCP for patients with mild gallstone pancreatitis is not recommended. The majority of obstructing stones will pass spontaneously and ERCP should be reserved for patients in whom the LFTs do not return to normal and persistent common bile duct stones are suspected. ${ }^{84-86}$

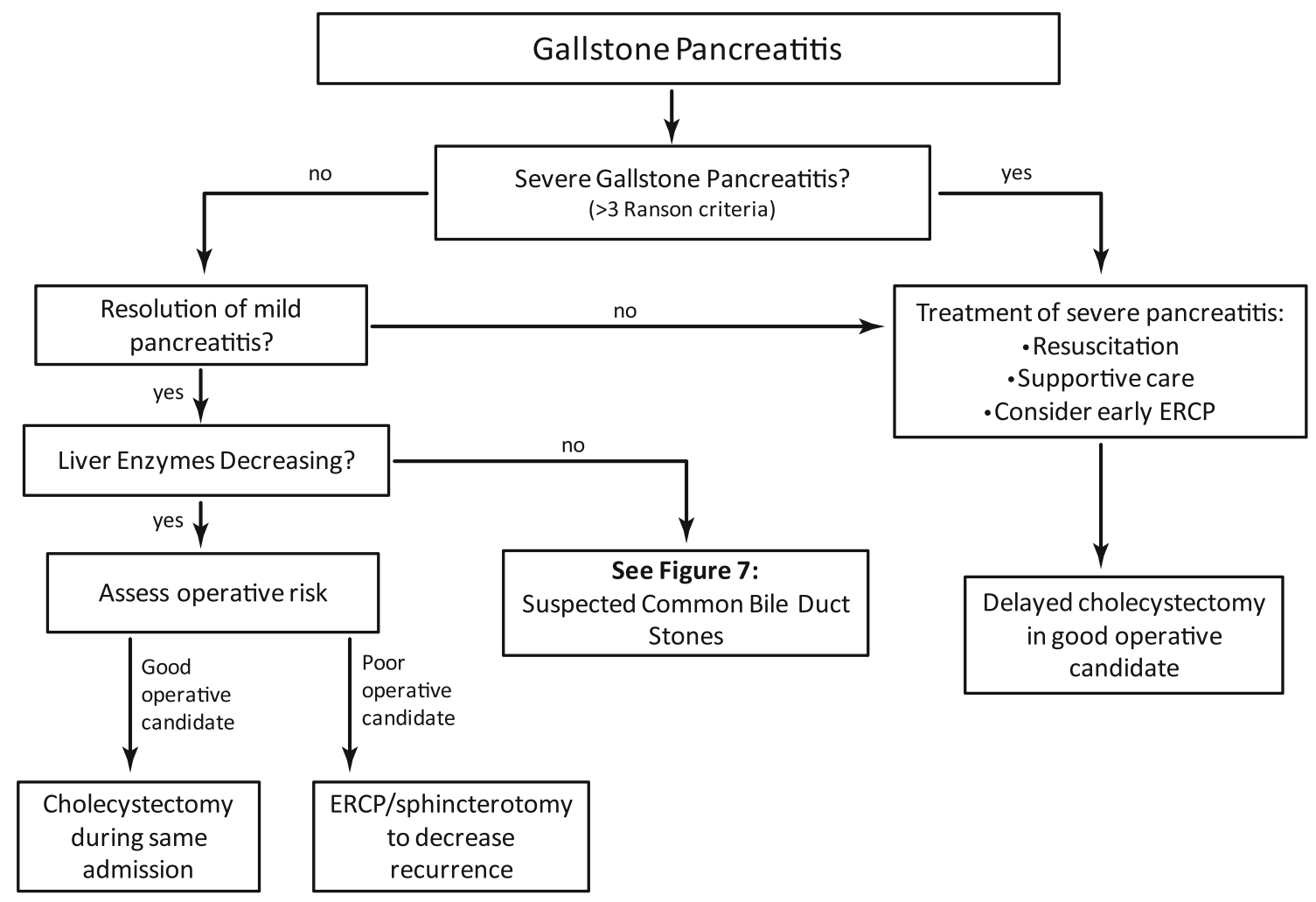

Fig. 7 Management algorithm for gallstone pancreatitis. Laparoscopic cholecystectomy is preferred in all cases, but conversion to open may be necessary and should not be considered a failure in management 
ERCP with endoscopic sphincterotomy has been used in patients with mild or severe gallstone pancreatitis who are elderly or are considered to be poor surgical candidates. ${ }^{2,23,42,74}$ Patients who undergo ERCP only for gallstone pancreatitis have a higher rate of recurrent pancreatitis and higher rates of gallbladder-related complications compared to patients who undergo cholecystectomy. ${ }^{74}$ In these patients, ERCP has been shown to reduce, but not eliminate, gallstone-related readmission rates. ${ }^{23}$

\section{Management of Cholangitis}

Ultimately, all patients with acute cholangitis will require biliary drainage and bile duct clearance as definitive management. ${ }^{37,87,88}$ Biliary drainage can be done electively in patients with mild cholangitis (those who respond to fluid resuscitation and antibiotics), within 24-48 h in patients with moderate cholangitis (those who do not respond to fluid resuscitation and antibiotics but with preserved organ function), and urgently for those with severe cholangitis (associated with organ dysfunction). ERCP with endoscopic drainage is the gold standard for the diagnosis and treatment of acute cholangitis ${ }^{3,87}$ and is preferred over both surgical and percutaneous biliary drainage. ${ }^{37}$ If endoscopic drainage is not possible, percutaneous transhepatic biliary drainage is also an option. An internal-external biliary catheter provides decompression and allows access to the biliary tree. If neither is possible, surgical decompression with CBD exploration and stone removal is indicated. If the patient is unstable and stone removal is not possible, T-tube drainage temporizes cholangitis and allows biliary access for eventual stone removal. For large impacted stones where ERCP, percutaneous methods, and/or open exploration are not possible, choledochoduodenostomy or choledochojejunostomy may be necessary.

\section{The Role of Intraoperative Cholangiography} in the Prevention of Bile Duct Injury

A recent population-based study demonstrated wide variation in the use of intraoperative cholangiography. ${ }^{89}$ IOC use ranged from 2 to $98 \%$ among surgeons and from 4 to $95 \%$ in hospitals in Texas. Uncertainty in the effectiveness of IOC in preventing bile duct injury and the multiple options for identification and removal of CBD stones likely contribute to the variation in use. In addition, over $40 \%$ of the variance in IOC use was due to hospital and surgeon factors, suggesting that surgeon or facility preference and not patient characteristics drive much of this decision. ${ }^{89}$

The routine use of IOC during cholecystectomy remains debated and controversial among surgeons. ${ }^{90-99}$ Advocates of routine IOC use characterize it as a system-level intervention that may prevent major bile duct injury, minimize the extent of injury, and protect against medical malpractice claims. ${ }^{91,92,95}$ Routine users also suggest that it is impossible to predict preoperatively which patients definitely have $\mathrm{CBD}$ stones and which are at increased risk of injury, lending support to routine over selective use. ${ }^{100}$

Critics of routine use cite the increased operative time and costs associated with IOC, as well as the small risk of complications. Two prospective studies reported that it takes about 15 min to perform an IOC. ${ }^{101,102}$ However, it may take significantly longer at hospitals where fluoroscopy is not readily available, surgeons are not skilled, and it is not routinely done. ${ }^{103}$

Little to no level 1 evidence exists regarding the efficacy of IOC in the prevention of bile duct injuries. Previous studies have potential weaknesses. Several populationbased studies using administrative and hospital discharge data from the 1990s have found that odds of common bile duct injury were $50-71 \%$ higher in patients who did not undergo IOC, ${ }^{91,92,104,105}$ while studies using more recent data have shown no significant difference. ${ }^{99,106}$ A recent randomized clinical trial in patients with low risk of common bile duct stones showed no statistically significant association between IOC and postoperative morbidity or readmission rate for retained common bile duct stones. ${ }^{107}$

Given the low incidence of bile duct injury during cholecystectomy, ${ }^{91,92,108}$ single-institution studies may be underpowered to demonstrate a difference. However, large-population-based studies are subject to selection bias. For example, rates of injury in cases where IOC is not performed by routine users (surgeons with $>75 \%$ IOC rate) have documented approximately a threefold increased risk of bile duct injury. This is mostly likely because the routine users were unable to perform an IOC in the setting of aberrant or obscured anatomy and not because IOC was not attempted, ${ }^{92}$ likewise when non-routine users have higher rates of injury when they did perform IOC (because they were unable to define the anatomy or suspected an injury)..$^{91,92}$

Cost estimates for performing IOC range from $\$ 100$ to 700. ${ }^{102,109-111}$ However, additional costs may be incurred for additional stone removal procedures, many of which may be unnecessary since it is estimated that nearly half of patients with common bile duct stones pass the stones spontaneously within weeks of cholecystectomy. ${ }^{112} \mathrm{~A}$ costeffectiveness analysis of routine IOC for the prevention of bile duct injury reported an additional cost of $\$ 87,143$ for every bile duct injury prevented. ${ }^{113}$ This study likely underestimates the cost as it did not take into account the high falsepositive rates and high rates of identification of asymptomatic CBD stones that would have passed spontaneously, leading to additional and unnecessary procedures. ${ }^{100,107,114,115}$

Given the frequency of cholecystectomy in the USA, increased costs per patient equate to considerable costs at 
the population level. IOC should be performed in cases where the "critical view of safety" is not achieved. ${ }^{3,116}$ The "critical view of safety" was first introduced by Strasberg et al. and requires the complete clearance of Calot's triangle of fat and fibrous tissue, dissection of the neck and body of the gallbladder from the gallbladder fossa, and direct visualization of the entry of the cystic duct and cystic artery into the gallbladder. ${ }^{16,117}$ Future studies evaluating the comparative effectiveness of IOC during cholecystectomy for bile duct injury and CBD stones are necessary to develop clear guidelines.

\section{Advances in Surgical Technique}

Cholecystectomy: Laparoscopic or Open?

In a large review of the literature, Gurusamy et al. ${ }^{7}$ report an overall perioperative mortality rate after cholecystectomy between 0 and $0.3 \%$. Complications of cholecystectomy include bile duct injury $(0.1-0.3 \%)$, bile leak $(0-0.1 \%)$, peritonitis $(0.2 \%)$, bleeding $(0.1-0.5 \%)$, intra-abdominal abscess $(0.1 \%)$, and wound infection. ${ }^{7}$ Cholecystectomy can be performed via a laparoscopic or open approach.

Laparoscopic cholecystectomy is performed in over $90 \%$ of elective cholecystectomies and $70 \%$ of emergent cholecystectomies. ${ }^{30,118}$ Laparoscopic cholecystectomy is associated with shorter hospital stays, faster return to work, and lower operative mortality compared to open cholecystectomy. In addition, no difference has been shown in the rates of bile duct injury, bile leak, or other operative complications between the two techniques. ${ }^{2,7,59,60}$ Laparoscopic cholecystectomy is associated with an increased risk of bladder, bowel, or vascular injury during trocar insertion. ${ }^{7}$ Factors predictive of conversion to open cholecystectomy include male gender, previous abdominal surgery, obesity, gallbladder wall thickening, suspicion of common bile duct stones, jaundice, acute cholecystitis, leukocytosis, and decreased surgeon experience. ${ }^{34,118}$ Skilled laparoscopic surgeons can and should attempt laparoscopic cholecystectomy even in the presence of the above risk factors for conversion to an open procedure. Conversion to open cholecystectomy should be considered early in high-risk patients or in cases where the safety of the patient would be compromised. However, conversion to open cholecystectomy should not be considered a failure in management.

\section{Single-Incision Laparoscopic Cholecystectomy}

Single-incision laparoscopic cholecystectomy (SILS) is being increasingly used in an effort to improve postoperative pain and recovery and decrease scarring. During SILS, several trocars are inserted through the umbilicus with a bridge of fascia between trocars. These sites are then united at the end of the procedure to allow for fascial closure. Alternatively, a single port or gelport may be used in the umbilicus to facilitate the insertion and manipulation of the trocars (Fig. 8). Lack of triangulation and clashing of instruments within the single umbilical port may make visualization difficult or frustrating. ${ }^{19,120} \mathrm{~A} 30^{\circ}$ laparoscopic camera should be used. Stay sutures can be passed through the abdominal wall and into the gallbladder to assist in retraction and exposure, and the gallbladder is removed via the umbilicus. ${ }^{119-124}$ An additional port may be required in patients with gallbladder inflammation, adhesions, or bleeding to ensure adequate visualization and safe dissection. ${ }^{119,121}$

Currently, SILS cholecystectomy is being performed in highly selected patients with a BMI of less than $40 \mathrm{~kg} / \mathrm{m}^{2}$, symptomatic cholelithiasis without complications of gallstones, and classified as American Society of Anesthesiology (ASA) grade I or II. ${ }^{120,122-124}$ SILS cholecystectomy is typically not attempted in patients with an umbilical hernia or previous upper abdominal surgery. ${ }^{120,124}$

The operating time for SILS cholecystectomy ranges from 35 to $180 \mathrm{~min},{ }^{120,122-124}$ significantly longer than traditional laparoscopic cholecystectomy and shorter than natural orifice transluminal endoscopic (NOTES) cholecystectomy. ${ }^{120,122,123}$ However, with increasing surgeon experience, the operating time for SILS cholecystectomy has been shown to decrease. ${ }^{124}$ Intraoperative blood loss is similar between SILS and traditional laparoscopic cholecystectomy. ${ }^{120,123}$ Greater than $90 \%$ of attempted SILS cholecystectomies can be performed successfully, with the majority of failed attempts being completed with a fourport laparoscopic cholecystectomy. ${ }^{120,122,124}$ Yeo et al. report that IOC can be performed successfully in $96 \%$ of patients undergoing SILS cholecystectomy, with $80 \%$ of

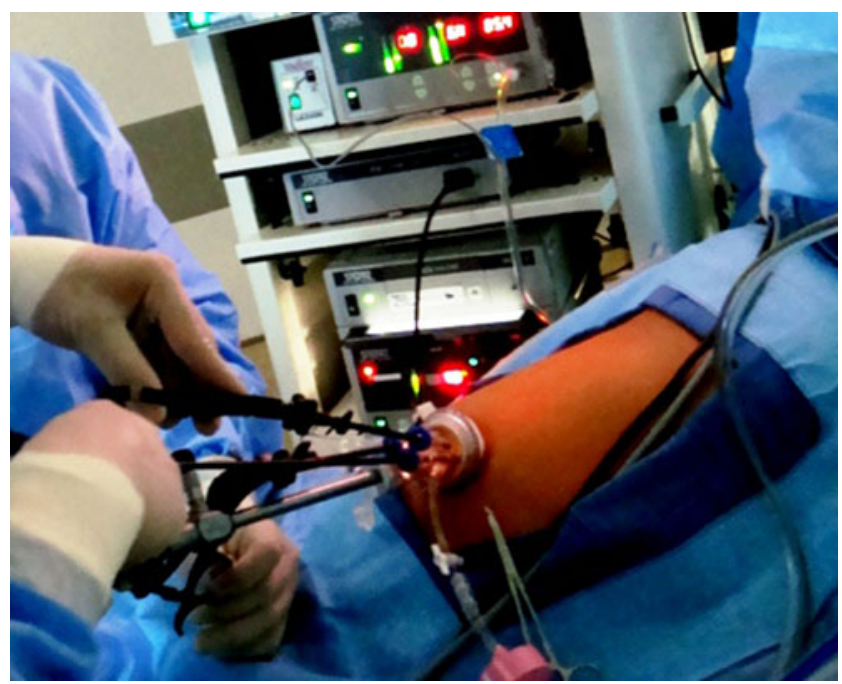

Fig. 8 Intraoperative photograph of port placement in single-incision laparoscopic cholecystectomy 
patients with visualized common bile duct stones being managed via a single port. ${ }^{124}$

Studies have shown mixed results regarding postoperative pain in patients undergoing SILS cholecystectomy compared to patients undergoing traditional laparoscopic cholecystectomy. ${ }^{120,123,125}$ There is concern that the larger fascial defect required for SILS cholecystectomy may result in higher rates of incisional hernia and wound complications, including seroma and hematoma. ${ }^{119,121,124}$ Complications of SILS cholecystectomy occur less often with increasing surgeon experience. ${ }^{119}$ Studies with longer follow-up time and those with broader inclusion criteria are needed to further evaluate the safety and efficacy of SILS cholecystectomy in the general population.

\section{Natural Orifice Transluminal Endoscopic Surgery}

NOTES is being used with increasing frequency for a variety of surgical procedures, and cholecystectomy is currently the most commonly performed NOTES procedure. ${ }^{121}$ Various methods have been used to obtain adequate visualization and positioning of the trocars during NOTES cholecystectomy. ${ }^{121}$ Most commonly, the endoscope is inserted transvaginally through a colpotomy, which is later closed with absorbable sutures. One or more trocars may be inserted through an umbilical port to help with the dissection, and transabdominal stay sutures may be placed through the gallbladder wall to aid in retraction and exposure of the triangle of Calot. The gallbladder is removed through the vagina. ${ }^{121,122}$

Navarra et al. ${ }^{122}$ report that NOTES cholecystectomy should not be performed in women with a history of pelvic inflammatory disease or previous pelvic surgery. Similarly, there is some concern regarding the effect of NOTES on sexual discomfort and future fertility and should be used cautiously in women desiring future pregnancy. ${ }^{122}$ The mean operating time for NOTES cholecystectomy is approximately $60 \mathrm{~min},{ }^{121,122}$ although it is likely that operating time will decrease with increasing surgeon experience. Complications are rare with NOTES cholecystectomy and include those of traditional laparoscopic cholecystectomy (bile leak, bleeding, liver or bowel injury), pelvic infection or inflammation, and hernia. ${ }^{122}$ Postoperative pain, conversion rates, length of stay, and readmission rates after NOTES cholecystectomy have been reported to be similar to those of SILS cholecystectomy and traditional laparoscopic cholecystectomy. ${ }^{122}$ Additional studies are required to evaluate long-term results and further elucidate which patients are candidates for NOTES cholecystectomy.

\section{Common Bile Duct Exploration}

Surgical common bile duct exploration should be performed in patients with common bile duct stones in whom a preoperative ERCP is unsuccessful in clearing the bile duct and in those without a preoperative ERCP in whom common bile duct stones are noted on IOC. ${ }^{3}$ Laparoscopic common duct exploration is associated with improved survival, lower readmission rates, and shorter hospital stays when compared to open duct exploration. ${ }^{31} \mathrm{~A}$ transcystic approach is recommended in the case of small common duct stones $(<6 \mathrm{~mm})$ and a cystic duct greater than $4 \mathrm{~mm}$ in diameter. Glucagon flushing (1-2 mg) may result in bile duct clearance, especially in the case of stones less than $2 \mathrm{~mm}$ in size. If unsuccessful, a helical basket may be passed through the cystic duct over a guide wire to extract stones under fluoroscopic guidance. If still unsuccessful, a choledochoscope may be employed to directly visualize and extract the stones after dilation of the cystic duct. ${ }^{3,14} \mathrm{~A}$ transductal approach is best in the case of large stones $(>6 \mathrm{~mm}$ ) but may be difficult when the common bile duct is less than $6 \mathrm{~mm}$ in diameter. Typically, choledochotomy is performed with or without sphincterotomy, with endoscopic extraction of the stones and flushing of the bile duct. ${ }^{3,14}$ With persistently impacted stones, drainage should be obtained with a straight tube or $\mathrm{T}$ tube in order to facilitate the future removal of stones. Conversion to an open procedure may be necessary. ${ }^{3,14}$

\section{Conclusion}

The majority of patients with gallstones are asymptomatic. When symptoms do arise, appropriate definitive management should be performed. Cholecystectomy, preferably laparoscopic, should be performed early in the course of biliary colic, acute cholecystitis, common bile duct stones, and mild gallstone pancreatitis. Preoperative ERCP with clearance of the bile duct or intraoperative cholangiogram with bile duct exploration should be performed in patients with suspected common bile duct stones. Evidence-based management of patients with gallbladder disease can result in decreased morbidity, mortality, and costs.

Funding This study was supported by grants from the National Institutes of Health (1K07CA130983-01A1, UL1RR029876, and T32 DK007639).

\section{References}

1. Bar-Meir S. Gallstones: prevalence, diagnosis and treatment. Isr Med Assoc J. 2001;3: 111-3.

2. Steiner CA, Bass EB, Talamini MA, Pitt HA, Steinberg EP. Surgical rates and operative mortality for open and laparoscopic cholecystectomy in Maryland. N Engl J Med. 1994;330: 403-8. 
3. Fischer JE, ed. Mastery of surgery. 5 ed. Philadelphia: Lippincott Williams \& Wilkins 2007.

4. Attili AF, Carulli N, Roda E, Barbara B, Capocaccia L, Menotti A, Okoliksanyi L, Ricci G, Capocaccia R, Festi D, et al. Epidemiology of gallstone disease in Italy: prevalence data of the Multicenter Italian Study on Cholelithiasis (M.I.COL.). Am J Epidemiol. 1995;141: 158-65.

5. Khang KU, Wargo JA. Gallstone disease in the elderly. In: Rosenthal RA, Zenilman ME, Katlic MR, editors. Principles and Practice of Geriatric Surgery. Verlag: Springer; 2001 pp. 690-710.

6. Sanson TG, O'Keefe KP. Evaluation of abdominal pain in the elderly. Emerg Med Clin North Am. 1996;14: 615-27.

7. Gurusamy KS, Davidson BR. Surgical treatment of gallstones. Gastroenterol Clin North Am. 2010;39: 229-44, viii.

8. Portincasa P, Moschetta A, Petruzzelli M, Palasciano G, Di Ciaula A, Pezzolla A. Gallstone disease: symptoms and diagnosis of gallbladder stones. Best Pract Res Clin Gastroenterol. 2006;20: 1017-29.

9. Festi D, Reggiani ML, Attili AF, Loria P, Pazzi P, Scaioli E, Capodicasa S, Romano F, Roda E, Colecchia A. Natural history of gallstone disease: expectant management or active treatment? Results from a population-based cohort study. J Gastroenterol Hepatol. 2010;25: 719-24.

10. Li JC, Lee DW, Lai CW, Li AC, Chu DW, Chan AC. Percutaneous cholecystostomy for the treatment of acute cholecystitis in the critically ill and elderly. Hong Kong Med J. 2004;10: 389-93.

11. McKay A, Abulfaraj M, Lipschitz J. Short- and long-term outcomes following percutaneous cholecystostomy for acute cholecystitis in high-risk patients. Surg Endosc. 2011;26(5): 1343-51

12. van Geenen EJ, van der Peet DL, Bhagirath P, Mulder CJ, Bruno MJ. Etiology and diagnosis of acute biliary pancreatitis. Nat Rev Gastroenterol Hepatol. 2010;7: 495-502.

13. Whitcomb DC. Clinical practice. Acute pancreatitis. N Engl J Med. 2006;354: 2142-50.

14. Shojaiefard A, Esmaeilzadeh M, Ghafouri A, Mehrabi A. Various techniques for the surgical treatment of common bile duct stones: a meta review. Gastroenterol Res Pract. 2009;2009: 840208.

15. Joseph T, Unver K, Hwang GL, Rosenberg J, Sze DY, Hashimi S, Kothary N, Louie JD, Kuo WT, Hofmann LV, Hovsepian DM. Percutaneous cholecystostomy for acute cholecystitis: ten-year experience. J Vasc Interv Radiol. 2011;23: 83-8 e1.

16. Kimura Y, Takada T, Kawarada Y, Nimura Y, Hirata K, Sekimoto M, Yoshida M, Mayumi T, Wada K, Miura F, Yasuda H, Yamashita Y, Nagino M, Hirota M, Tanaka A, Tsuyuguchi T, Strasberg SM, Gadacz TR. Definitions, pathophysiology, and epidemiology of acute cholangitis and cholecystitis: Tokyo guidelines. J Hepatobiliary Pancreat Surg. 2007;14: 15-26.

17. Madrazo BL, Francis I, Hricak H, Sandler MA, Hudak S, Gitschlag K. Sonographic findings in perforation of the gallbladder. AJR Am J Roentgenol. 1982;139: 491-6.

18. Tsai MJ, Chen JD, Tiu CM, Chou YH, Hu SC, Chang CY. Can acute cholecystitis with gallbladder perforation be detected preoperatively by computed tomography in ED? Correlation with clinical data and computed tomography features. Am J Emerg Med. 2009;27: 574-81.

19. Costi R, Mazzeo A, Tartamella F, Manceau C, Vacher B, Valverde A. Cholecystocholedocholithiasis: a case-control study comparing the short- and long-term outcomes for a "laparoscopyfirst" attitude with the outcome for sequential treatment (systematic endoscopic sphincterotomy followed by laparoscopic cholecystectomy). Surg Endosc. 2010;24: 51-62.

20. Kharbutli B, Velanovich V. Management of preoperatively suspected choledocholithiasis: a decision analysis. J Gastrointest Surg. 2008;12: 1973-80.
21. Urbach DR, Khajanchee YS, Jobe BA, Standage BA, Hansen PD, Swanstrom LL. Cost-effective management of common bile duct stones: a decision analysis of the use of endoscopic retrograde cholangiopancreatography (ERCP), intraoperative cholangiography, and laparoscopic bile duct exploration. Surg Endosc. 2001;15: 4-13.

22. Uhl W, Warshaw A, Imrie C, Bassi C, McKay CJ, Lankisch PG, Carter R, Di Magno E, Banks PA, Whitcomb DC, Dervenis C, Ulrich CD, Satake K, Ghaneh P, Hartwig W, Werner J, McEntee G, Neoptolemos JP, Buchler MW. IAP guidelines for the surgical management of acute pancreatitis. Pancreatology. 2002;2: 565-73.

23. Trust MD, Sheffield KM, Boyd CA, Benarroch-Gampel J, Zhang D, Townsend CM, Jr., Riall TS. Gallstone pancreatitis in older patients: are we operating enough? Surgery. 2011;150: 515-25.

24. Gurusamy KS, Samraj K. Early versus delayed laparoscopic cholecystectomy for acute cholecystitis. Cochrane Database Syst Rev. 2006;18(4): CD005440.

25. Gurusamy KS, Samraj K, Fusai G, Davidson BR. Early versus delayed laparoscopic cholecystectomy for biliary colic. Cochrane Database Syst Rev. 2008;8(4): CD007196.

26. LaFemina J, Sokal SM, Chang Y, McGrath D, Berger DL. Effect of medical or surgical admission on outcome of patients with gallstone pancreatitis and common bile duct stones. J Gastrointest Surg. 2008;12: 1554-60.

27. Nebiker CA, Frey DM, Hamel CT, Oertli D, Kettelhack C. Early versus delayed cholecystectomy in patients with biliary acute pancreatitis. Surgery. 2009;145: 260-4.

28. Riall TS, Zhang D, Townsend CM, Jr., Kuo YF, Goodwin JS. Failure to perform cholecystectomy for acute cholecystitis in elderly patients is associated with increased morbidity, mortality, and cost. J Am Coll Surg. 2010;210: 668-77, 77-9.

29. Rosing DK, de Virgilio C, Yaghoubian A, Putnam BA, El Masry M, Kaji A, Stabile BE. Early cholecystectomy for mild to moderate gallstone pancreatitis shortens hospital stay. J Am Coll Surg. 2007;205: 762-6.

30. Sheffield KM, Ramos KE, Djukom CD, Jimenez CJ, Mileski WJ, Kimbrough TD, Townsend CM, Jr., Riall TS. Implementation of a critical pathway for complicated gallstone disease: translation of population-based data into clinical practice. J Am Coll Surg. 2011;212: 835-43.

31. Stromberg C, Nilsson M. Nationwide study of the treatment of common bile duct stones in Sweden between 1965 and 2009. Br J Surg. 2011;98: 1766-74.

32. American College of Radiology ACR Appropriateness Criteria: right upper quadrant pain. 2010 [cited March 6, 2012]; Available from: http://www.acr.org/SecondaryMainMenuCategories/quality_ safety/app_criteria/pdf/ExpertPanelonGastrointestinalimaging/ RightUpperQuadrantPainDoc13.aspx

33. Benarroch-Gampel J, Boyd CA, Sheffield KM, Townsend CM, Jr., Riall TS. Overuse of CT in patients with complicated gallstone disease. J Am Coll Surg. 2011;213: 524-30.

34. Ou ZB, Li SW, Liu CA, Tu B, Wu CX, Ding X, Liu ZJ, Sun K, Feng HY, Gong JP. Prevention of common bile duct injury during laparoscopic cholecystectomy. Hepatobiliary Pancreat Dis Int. 2009;8: 414-7.

35. Winbladh A, Gullstrand P, Svanvik J, Sandstrom P. Systematic review of cholecystostomy as a treatment option in acute cholecystitis. HPB (Oxford). 2009;11: 183-93.

36. Tulchinsky M, Colletti PM, Allen TW. Hepatobiliary scintigraphy in acute cholecystitis. Semin Nucl Med. 2012;42: 84-100.

37. Lee JG. Diagnosis and management of acute cholangitis. Nat Rev Gastroenterol Hepatol. 2009;6: 533-41.

38. Brink JA, Ferrucci JT. Use of CT for predicting gallstone composition: a dissenting view. Radiology. 1991;178: 633-4.

39. Shakespear JS, Shaaban AM, Rezvani M. CT findings of acute cholecystitis and its complications. AJR Am J Roentgenol. 2010;194: 1523-9. 
40. O'Neill DE, Saunders MD. Endoscopic ultrasonography in diseases of the gallbladder. Gastroenterol Clin North Am. 2010;39: 289-305, ix

41. Saad WE, Ginat D. Computed tomography and magnetic resonance cholangiography. Tech Vasc Interv Radiol. 2008;11: 7489 .

42. Bignell M, Dearing M, Hindmarsh A, Rhodes M. ERCP and endoscopic sphincterotomy (ES): a safe and definitive management of gallstone pancreatitis with the gallbladder left in situ. J Gastrointest Surg. 2011;15: 2205-10.

43. Masci E, Toti G, Mariani A, Curioni S, Lomazzi A, Dinelli M, Minoli G, Crosta C, Comin U, Fertitta A, Prada A, Passoni GR, Testoni PA. Complications of diagnostic and therapeutic ERCP: a prospective multicenter study. Am J Gastroenterol. 2001;96: 417-23.

44. Salminen P, Laine S, Gullichsen R. Severe and fatal complications after ERCP: analysis of 2555 procedures in a single experienced center. Surg Endosc. 2008;22: 1965-70.

45. Siiki A, Tamminen A, Tomminen T, Kuusanmaki P. ERCP procedures in a Finnish community hospital: a retrospective analysis of 1207 cases. Scand J Surg. 2012;101: 45-50

46. Canfield AJ, Hetz SP, Schriver JP, Servis HT, Hovenga TL, Cirangle PT, Burlingame BS. Biliary dyskinesia: a study of more than 200 patients and review of the literature. J Gastrointest Surg. 1998;2: 443-8.

47. Ponsky TA, DeSagun R, Brody F. Surgical therapy for biliary dyskinesia: a meta-analysis and review of the literature. J Laparoendosc Adv Surg Tech A. 2005;15: 439-42.

48. Hansel SL, DiBaise JK. Functional gallbladder disorder: gallbladder dyskinesia. Gastroenterol Clin North Am. 2010;39: 369-79, $\mathrm{x}$.

49. Morris-Stiff G, Falk G, Kraynak L, Rosenblatt S. The cholecystokin provocation HIDA test: recreation of symptoms is superior to ejection fraction in predicting medium-term outcomes. J Gastrointest Surg. 2011;15: 345-9.

50. Barie PS, Eachempati SR. Acute acalculous cholecystitis. Gastroenterol Clin North Am. 2010;39: 343-57, x.

51. Huffman JL, Schenker S. Acute acalculous cholecystitis: a review. Clin Gastroenterol Hepatol. 2010;8: 15-22.

52. Wang AJ, Wang TE, Lin CC, Lin SC, Shih SC. Clinical predictors of severe gallbladder complications in acute acalculous cholecystitis. World J Gastroenterol. 2003;9: 2821-3.

53. McSherry CK, Ferstenberg H, Calhoun WF, Lahman E, Virshup $\mathrm{M}$. The natural history of diagnosed gallstone disease in symptomatic and asymptomatic patients. Ann Surg. 1985;202: 59-63.

54. Graham SM, Flowers JL, Schweitzer E, Bartlett ST, Imbembo AL. The utility of prophylactic laparoscopic cholecystectomy in transplant candidates. Am J Surg. 1995; 169: 44-8; discussion 8-9.

55. Richardson WS, Surowiec WJ, Carter KM, Howell TP, Mehra MR, Bowen JC. Gallstone disease in heart transplant recipients. Ann Surg. 2003;237: 273-6.

56. Aucott JN, Cooper GS, Bloom AD, Aron DC. Management of gallstones in diabetic patients. Arch Intern Med. 1993;153: 1053-8.

57. Friedman LS, Roberts MS, Brett AS, Marton KI. Management of asymptomatic gallstones in the diabetic patient. A decision analysis. Ann Intern Med. 1988;109: 913-9.

58. Ransohoff DF, Miller GL, Forsythe SB, Hermann RE. Outcome of acute cholecystitis in patients with diabetes mellitus. Ann Intern Med. 1987;106: 829-32.

59. Keus F, de Jong JA, Gooszen HG, van Laarhoven CJ. Laparoscopic versus open cholecystectomy for patients with symptomatic cholecystolithiasis. Cochrane Database Syst Rev. 2006: CD006231.

60. Zacks SL, Sandler RS, Rutledge R, Brown RS, Jr. A populationbased cohort study comparing laparoscopic cholecystectomy and open cholecystectomy. Am J Gastroenterol. 2002;97(2): 334-40.
61. Chandler CF, Lane JS, Ferguson P, Thompson JE, Ashley SW. Prospective evaluation of early versus delayed laparoscopic cholecystectomy for treatment of acute cholecystitis. Am Surg. 2000;66: 896-900.

62. Jarvinen HJ, Hastbacka J. Early cholecystectomy for acute cholecystitis: a prospective randomized study. Ann Surg. 1980;191: 501-5.

63. Johansson M, Thune A, Blomqvist A, Nelvin L, Lundell L. Management of acute cholecystitis in the laparoscopic era: results of a prospective, randomized clinical trial. J Gastrointest Surg. 2003; 7: 642-5.

64. Lahtinen J, Alhava EM, Aukee S. Acute cholecystitis treated by early and delayed surgery. A controlled clinical trial. Scand J Gastroenterol. 1978;13: 673-8.

65. Lai PB, Kwong KH, Leung KL, Kwok SP, Chan AC, Chung SC, Lau WY. Randomized trial of early versus delayed laparoscopic cholecystectomy for acute cholecystitis. Br J Surg. 1998;85: 764 7.

66. Lo CM, Liu CL, Fan ST, Lai EC, Wong J. Prospective randomized study of early versus delayed laparoscopic cholecystectomy for acute cholecystitis. Ann Surg. 1998;227: 461-7.

67. McArthur P, Cuschieri A, Shields R, Sells RA. Controlled clinical trial comparing early with interval cholecystectomy for acute cholecystitis. Proc R Soc Med. 1975;68: 676-8.

68. Norrby S, Herlin P, Holmin T, Sjodahl R, Tagesson C. Early or delayed cholecystectomy in acute cholecystitis? A clinical trial. Br J Surg. 1983;70: 163-5.

69. Shikata S, Noguchi Y, Fukui T. Early versus delayed cholecystectomy for acute cholecystitis: a meta-analysis of randomized controlled trials. Surg Today. 2005;35: 553-60.

70. Siddiqui T, MacDonald A, Chong PS, Jenkins JT. Early versus delayed laparoscopic cholecystectomy for acute cholecystitis: a meta-analysis of randomized clinical trials. Am J Surg. 2008;195: $40-7$.

71. Boerma D, Rauws EA, Keulemans YC, Janssen IM, Bolwerk CJ, Timmer R, Boerma EJ, Obertop H, Huibregtse K, Gouma DJ. Wait-and-see policy or laparoscopic cholecystectomy after endoscopic sphincterotomy for bile-duct stones: a randomised trial. Lancet. 2002;360: 761-5.

72. Lau JY, Leow CK, Fung TM, Suen BY, Yu LM, Lai PB, Lam YH, Ng EK, Lau WY, Chung SS, Sung JJ. Cholecystectomy or gallbladder in situ after endoscopic sphincterotomy and bile duct stone removal in Chinese patients. Gastroenterology. 2006;130: 96-103.

73. Armstrong CP, Taylor TV, Jeacock J, Lucas S. The biliary tract in patients with acute gallstone pancreatitis. Br J Surg. 1985;72: $551-5$.

74. Kaw M, Al-Antably Y, Kaw P. Management of gallstone pancreatitis: cholecystectomy or ERCP and endoscopic sphincterotomy. Gastrointest Endosc. 2002;56: 61-5.

75. Ranson JH. The role of surgery in the management of acute pancreatitis. Ann Surg. 1990;211: 382-93.

76. Uhl W, Muller CA, Krahenbuhl L, Schmid SW, Scholzel S, Buchler MW. Acute gallstone pancreatitis: timing of laparoscopic cholecystectomy in mild and severe disease. Surg Endosc. 1999;13: 1070-6.

77. Judkins SE, Moore EE, Witt JE, Barnett CC, Biffl WL, Burlew CC, Johnson JL. Surgeons provide definitive care to patients with gallstone pancreatitis. Am J Surg. 2011;202: 673-7; discussion 7-8.

78. Nguyen GC, Boudreau H, Jagannath SB. Hospital volume as a predictor for undergoing cholecystectomy after admission for acute biliary pancreatitis. Pancreas. 2010;39: e42-7.

79. Cuschieri A, Lezoche E, Morino M, Croce E, Lacy A, Toouli J, Faggioni A, Ribeiro VM, Jakimowicz J, Visa J, Hanna GB. E.A.E.S. multicenter prospective randomized trial comparing 
two-stage vs single-stage management of patients with gallstone disease and ductal calculi. Surg Endosc. 1999;13: 952-7.

80. Martin DJ, Vernon DR, Toouli J. Surgical versus endoscopic treatment of bile duct stones. Cochrane Database Syst Rev. 2006: CD003327.

81. Rhodes M, Sussman L, Cohen L, Lewis MP. Randomised trial of laparoscopic exploration of common bile duct versus postoperative endoscopic retrograde cholangiography for common bile duct stones. Lancet. 1998;17;351(9097): 159-61.

82. Gurusamy K, Sahay SJ, Burroughs AK, Davidson BR. Systematic review and meta-analysis of intraoperative versus preoperative endoscopic sphincterotomy in patients with gallbladder and suspected common bile duct stones. Br J Surg. 2011;98: 908-16.

83. Rabago LR, Vicente C, Soler F, Delgado M, Moral I, Guerra I, Castro JL, Quintanilla E, Romeo J, Llorente R, Vazquez Echarri J, Martinez-Veiga JL, Gea F. Two-stage treatment with preoperative endoscopic retrograde cholangiopancreatography (ERCP) compared with single-stage treatment with intraoperative ERCP for patients with symptomatic cholelithiasis with possible choledocholithiasis. Endoscopy. 2006;38: 779-86.

84. Acosta JM, Ledesma CL. Gallstone migration as a cause of acute pancreatitis. N Engl J Med. 1974;290: 484-7.

85. Petrov MS, van Santvoort HC, Besselink MG, van der Heijden GJ, van Erpecum KJ, Gooszen HG. Early endoscopic retrograde cholangiopancreatography versus conservative management in acute biliary pancreatitis without cholangitis: a meta-analysis of randomized trials. Ann Surg. 2008;247: 250-7.

86. Forsmark CE, Baillie J. AGA Institute technical review on acute pancreatitis. Gastroenterology. 2007;132: 2022-44.

87. Agarwal N, Sharma BC, Sarin SK. Endoscopic management of acute cholangitis in elderly patients. World J Gastroenterol. 2006; 12: 6551-5.

88. Salek J, Livote E, Sideridis K, Bank S. Analysis of risk factors predictive of early mortality and urgent ERCP in acute cholangitis. J Clin Gastroenterol. 2009;43: 171-5.

89. Sheffield KM, Han Y, Kuo YF, Townsend CM, Jr., Goodwin JS, Riall TS. Variation in the use of intraoperative cholangiography during cholecystectomy. J Am Coll Surg. 2012;214: 668-79.

90. Akolekar D, Nixon SJ, Parks RW. Intraoperative cholangiography in modern surgical practice. Dig Surg. 2009;26: 130-4.

91. Flum DR, Dellinger EP, Cheadle A, Chan L, Koepsell T. Intraoperative cholangiography and risk of common bile duct injury during cholecystectomy. JAMA. 2003;289: 1639-44.

92. Flum DR, Koepsell T, Heagerty P, Sinanan M, Dellinger EP. Common bile duct injury during laparoscopic cholecystectomy and the use of intraoperative cholangiography: adverse outcome or preventable error? Arch Surg. 2001;136: 1287-92.

93. Hamad MA, Nada AA, Abdel-Atty MY, Kawashti AS. Major biliary complications in 2,714 cases of laparoscopic cholecystectomy without intraoperative cholangiography: a multicenter retrospective study. Surg Endosc. 2011;25: 3747-51.

94. Horwood J, Akbar F, Davis K, Morgan R. Prospective evaluation of a selective approach to cholangiography for suspected common bile duct stones. Ann R Coll Surg Engl. 2010;92: 206-10.

95. Massarweh NN, Flum DR. Role of intraoperative cholangiography in avoiding bile duct injury. J Am Coll Surg. 2007;204: 65664.

96. Nickkholgh A, Soltaniyekta S, Kalbasi H. Routine versus selective intraoperative cholangiography during laparoscopic cholecystectomy: a survey of 2,130 patients undergoing laparoscopic cholecystectomy. Surg Endosc. 2006;20: 868-74.

97. Nuzzo G, Giuliante F, Giovannini I, Ardito F, D'Acapito F, Vellone M, Murazio M, Capelli G. Re: role of intraoperative cholangiography in avoiding bile duct injury. J Am Coll Surg. 2007;205: e5-6; author reply.
98. Traverso LW. Intraoperative cholangiography lowers the risk of bile duct injury during cholecystectomy. Surg Endosc. 2006;20: 1659-61.

99. Nuzzo G, Giuliante F, Giovannini I, Ardito F, D'Acapito F, Vellone M, Murazio M, Capelli G. Bile duct injury during laparoscopic cholecystectomy: results of an Italian national survey on 56591 cholecystectomies. Arch Surg. 2005;140: 986-92.

100. Byrne MF, McLoughlin MT, Mitchell RM, Gerke H, Kim K, Pappas TN, Branch MS, Jowell PS, Baillie J. For patients with predicted low risk for choledocholithiasis undergoing laparoscopic cholecystectomy, selective intraoperative cholangiography and postoperative endoscopic retrograde cholangiopancreatography is an effective strategy to limit unnecessary procedures. Surg Endosc. 2009;23: 1933-7.

101. Catheline JM, Turner R, Paries J. Laparoscopic ultrasonography is a complement to cholangiography for the detection of choledocholithiasis at laparoscopic cholecystectomy. Br J Surg. 2002;89: 1235-9.

102. Halpin VJ, Dunnegan D, Soper NJ. Laparoscopic intracorporeal ultrasound versus fluoroscopic intraoperative cholangiography: after the learning curve. Surg Endosc. 2002;16: 336-41.

103. Massarweh NN, Devlin A, Elrod JA, Symons RG, Flum DR. Surgeon knowledge, behavior, and opinions regarding intraoperative cholangiography. J Am Coll Surg. 2008;207: 821-30.

104. Waage A, Nilsson M. Iatrogenic bile duct injury: a populationbased study of 152776 cholecystectomies in the Swedish Inpatient Registry. Arch Surg. 2006;141: 1207-13.

105. Fletcher DR, Hobbs MS, Tan P, Valinsky LJ, Hockey RL, Pikora TJ, Knuiman MW, Sheiner HJ, Edis A. Complications of cholecystectomy: risks of the laparoscopic approach and protective effects of operative cholangiography: a population-based study. Ann Surg. 1999;229: 449-57.

106. Giger U, Ouaissi M, Schmitz SF, Krahenbuhl S, Krahenbuhl L. Bile duct injury and use of cholangiography during laparoscopic cholecystectomy. Br J Surg. 2011;98: 391-6.

107. Khan OA, Balaji S, Branagan G, Bennett DH, Davies N. Randomized clinical trial of routine on-table cholangiography during laparoscopic cholecystectomy. Br J Surg. 2011;98: 362-7.

108. Ford JA, Soop M, Du J, Loveday BP, Rodgers M. Systematic review of intraoperative cholangiography in cholecystectomy. $\mathrm{Br}$ J Surg. 2011;99: 160-7.

109. Podnos YD, Gelfand DV, Dulkanchainun TS, Wilson SE, Cao S, Ji P, Ortiz JA, Imagawa DK. Is intraoperative cholangiography during laparoscopic cholecystectomy cost effective? Am J Surg. 2001;182: 663-9.

110. Traverso LW, Hargrave K. A prospective cost analysis of laparoscopic cholecystectomy. Am J Surg. 1995;169: 503-6.

111. Livingston EH, Miller JA, Coan B, Rege RV. Costs and utilization of intraoperative cholangiography. J Gastrointest Surg. 2007;11: 1162-7.

112. Collins C, Maguire D, Ireland A, Fitzgerald E, O'Sullivan GC. A prospective study of common bile duct calculi in patients undergoing laparoscopic cholecystectomy: natural history of choledocholithiasis revisited. Ann Surg. 2004;239: 28-33.

113. Flum DR, Flowers C, Veenstra DL. A cost-effectiveness analysis of intraoperative cholangiography in the prevention of bile duct injury during laparoscopic cholecystectomy. J Am Coll Surg. 2003;196: 385-93.

114. Buddingh KT, Weersma RK, Savenije RA, van Dam GM, Nieuwenhuijs VB. Lower rate of major bile duct injury and increased intraoperative management of common bile duct stones after implementation of routine intraoperative cholangiography. J Am Coll Surg. 2011;213: 267-74.

115. Nugent N, Doyle M, Mealy K. Low incidence of retained common bile duct stones using a selective policy of biliary imaging. Surgeon. 2005;3: 352-6. 
116. Sanjay P, Fulke JL, Exon DJ. 'Critical view of safety' as an alternative to routine intraoperative cholangiography during laparoscopic cholecystectomy for acute biliary pathology. J Gastrointest Surg. 2010;14: 1280-4.

117. Strasberg SM, Hertl M, Soper NJ. An analysis of the problem of biliary injury during laparoscopic cholecystectomy. J Am Coll Surg. 1995;180: 101-25.

118. Kama NA, Doganay M, Dolapci M, Reis E, Atli M, Kologlu M. Risk factors resulting in conversion of laparoscopic cholecystectomy to open surgery. Surg Endosc. 2001;15: 965-8.

119. Fransen S, Stassen L, Bouvy N. Single incision laparoscopic cholecystectomy: a review on the complications. J Minim Access Surg. 2012;8: 1-5.

120. Sinan H, Demirbas S, Ozer MT, Sucullu I, Akyol M. Singleincision laparoscopic cholecystectomy versus laparoscopic cholecystectomy: a prospective randomized study. Surg Laparosc Endosc Percutan Tech. 2012;22: 12-6.

121. Chamberlain RS, Sakpal SV. A comprehensive review of singleincision laparoscopic surgery (SILS) and natural orifice transluminal endoscopic surgery (NOTES) techniques for cholecystectomy. J Gastrointest Surg. 2009;13: 1733-40.

122. Navarra G, La Malfa G, Lazzara S, Ullo G, Curro G. SILS and NOTES cholecystectomy: a tailored approach. J Laparoendosc Adv Surg Tech A. 2010;20: 511-4.

123. Tsimoyiannis EC, Tsimogiannis KE, Pappas-Gogos G, Farantos C, Benetatos N, Mavridou P, Manataki A. Different pain scores in single transumbilical incision laparoscopic cholecystectomy versus classic laparoscopic cholecystectomy: a randomized controlled trial. Surg Endosc. 2010;24: 1842-8.

124. Yeo D, Mackay S, Martin D. Single-incision laparoscopic cholecystectomy with routine intraoperative cholangiography and common bile duct exploration via the umbilical port. Surg Endosc. 2011.

125. Joseph S, Moore BT, Sorensen GB, Earley JW, Tang F, Jones P, Brown KM. Single-incision laparoscopic cholecystectomy: a comparison with the gold standard. Surg Endosc. 2011;25(9): 3008-15.

\section{CME QUESTIONS}

1. Prophylactic cholecystectomy for asymptomatic cholelithiasis is indicated in all of the following patients EXCEPT:

a. A 57-year old man awaiting a heart transplant with documented cholelithiasis

b. A 23-year old female with known sickle cell anemia

c. A 45-year old male with diabetes

d. A 65-year old woman with a $4 \mathrm{~cm}$ gallstone

e. A 65-year old woman with suspected porcelain gallbladder on abdominal xray

2. A 28-year old woman who is 18 weeks pregnant presents with epigastric pain. Serum amylase is $708 \mathrm{U} / \mathrm{L}$ and lipase is $951 \mathrm{U} / \mathrm{L}$. Amylase and lipase return to normal over 48 hours. LFTs are initially elevated and return to normal. Ultrasound demonstrates cholelithiasis and a normal common bile duct diameter. Which of the following is the next appropriate step in the management of this patient?

a. ERCP to clear the bile duct

b. Nonoperative management, since the risk of recurrent pancreatitis during pregnancy is low

c. MRCP to make a definitive diagnosis, since the radiation exposure is low d. Laparoscopic cholecystectomy during the same admission

e. Delayed cholecystectomy

3. A 72-year old man was recently admitted for congestive heart failure (CHF) after acute myocardial infarction (MI). He has since developed acute respiratory distress syndrome (ARDS) requiring mechanical ventilation. On examination the patients is febrile and has gram-negative bacteremia on blood culture. Bedside ultrasound demonstrates multiple gallstones, a thickened gallbladder wall and pericholecystic fluid, but no gallstones. He is tender in the right upper quadrant. The most appropriate next step in the management of this patient is:
a. Antibiotics and hemodynamic support only
b. Laparoscopic cholecystectomy
c. ERCP with sphincterotomy
d. Percutaneous transhepatic cholangiography with catheter drainage
e. Percutaneous cholecystostomy

4. A patient is admitted with jaundice and right upper quadrant pain. The patient is afebrile and has normal white blood cell count. Serum bilirubin is elevated and ultrasound demonstrates a dilated common bile duct. Serum bilirubin increases over 24 hours. Which of the following would NOT be considered appropriate management of this patient, depending on facility and surgeon expertise?

a. Continued observation

b. ERCP with sphincterotomy and bile duct clearance, followed by cholecystectomy

c. Cholecystectomy with intraoperative cholangiogram (IOC) and bile duct exploration

d. Cholecystectomy with IOC and intraoperative ERCP

e. Cholecystectomy with IOC and postoperative ERCP

5. A 43-year old diabetic female is admitted with fever, right upper quadrant pain, and leukocytosis. An abdominal ultrasound is inconclusive due to body habitus. The next most appropriate imaging test is:

a. Magnetic resonance cholangiopancreatography (MRCP)

b. Hepatobiliary iminodiacetic acid (HIDA) scan

c. Computed tomography of the abdomen and pelvis

d. Endoscopic ultrasound (EUS)

e. Repeat the abdominal ultrasound with lower frequency sound wave

Answers:

1. c

2. d

3. e

4. a

5. $b$ 